\title{
PROBLEMS OF BIG DATA ADOPTION IN THE HEALTHCARE INDUSTRIES
}

\author{
Surya Kant Pall*, Subhodeep Mukherjee2, Manish Mohan Baral2, Shilpee Aggarwal3 \\ 1. Department of Mathematics, School of Basic Sciences and Research, Sharda University, Greater Noida, Uttar Pradesh, India \\ 2. Department of Operations, GITAM Institute of Management, Visakhapatnam, Andhra Pradesh, India \\ 3. Department of Management, Maharaja Agrasen Institute of Management Studies, Delhi, India
}

Correspondence: suryakantpal6676@gmail.com

\begin{abstract}
Big data offers the knowledge required for healthcare providers to streamline customer service processes that customize healthcare and create best practices for communicating with clients or patients. A more detailed and customized experience can be offered to customers. But there are many challenges that healthcare organizations are facing. The research aims to study big data challenges in the healthcare sector. A literature review is performed to discover big data problems in healthcare. A questionnaire is utilized for the survey research in the hospitals. Target populations are the staff who are working in the hospitals. For analysis, exploratory factor analysis is being performed. All the challenges are grouped into five factors. All the parameters are satisfied for the study.
\end{abstract}

\section{KEYWORDS}

Big Data, Challenges, Healthcare, India, Management

\section{INTRODUCTION}

The healthcare sector is among the most extensive and mature sectors globally, producing much value. The focus of healthcare management has shifted from diseasecentred to patient-centred models worldwide. [1] The growth of the healthcare delivery model based on values and the patient-centred care movement is guided by a philosophy of educating healthcare supremacy and lowering costs. In healthcare organizations, the volume and demand for big data (BD) are gradually increasing. It is critical to monitor and evaluate massive amounts of health data to provide effective patient-centred treatment. [2] Because of the variety and volume of data sources that have grown over the last two decades, outdated data processing implementations cannot analyse 'Big Data' (BD). New and creative BD tools and technologies are required to reach and exceed the potential of health data management.

Many healthcare organizations have made substantial efforts to combine vast data resources and advanced technology to address this constraint. Electronic health 
records (EHRs) that use BD analytics for major disease assessments and epidemiological research performance can be considered breakthroughs in medical information management. [3] Despite attempts to develop successful BD systems, several health organizations have faced early failure since implementing these new systems. [3] BD is widely accepted to explain separate entities' management processes across sectors. Therefore, due to predictable and unpredictable obstacles, a substantial number of organizations had encountered early failures in the implementation of healthcare BD. Barriers to such programs may come from a number of sources, including organizations, physicians, patients, or governments. This study describes the challenges faced by the healthcare sectors in the adoption of BD in their systems.

\section{LITERATURE REVIEW}

\section{BIG DATA}

In recent years, the word "BD" has become increasingly common around the globe. Whether it concerns business or academia, almost every research field produces and analyzes BD for multiple purpose. [4] The BD definition includes velocity and variety in addition to volume. The rate at which data is collected is called velocity. It makes it accessible for further examination. The standard definition of BD has been these three $V$ 's. While other individuals have added many other Vs to this description,' veracity' remains the most agreed 4th $\vee$. [5]

The most challenging job with regard to this massive volume of knowledge that can be structured and unorganized is its management.[6] Conventional programming is unmanageable for BD, so we need advanced applications and programming to utilize quick and financially savvy excellent quality, registering assets for such assignments. Artificial consciousness and present-day combination calculations should be used to sort out this gigantic measure of information. To utilize neural organizations and other Al procedures to accomplish robotized dynamics.

\section{BIG DATA IN HEALTHCARE}

$\mathrm{BD}$ is a low-cost, high-volume, high-speed, and highvelocity data processing system that improves insight, decision-making, and process automation. BD was used in several sectors to replace the conventional database framework to allow the appropriate management and analysis of extensive databases [7] Healthcare BD, also referred to as medical $B D$, plays a vital role in many hospitals and medical clinics' decision-making processes. Medical institutions build knowledge assets with high volume, velocity, value, and variety. Practical approaches should be used to analyses this type of data to improve decision-making. Medical BD comes in various styles and shapes; they're usually unstructured and complex, so they need a sound management system to make the most of them [8], using conventional data processing techniques or software. The BD method of data mining will collect practical knowledge from massive databases of large sizes. [9] Also, data mining association rules help data mining, creating rules in deciding its association between various items.

\section{CHALLENGES OF BIG DATA IN HEALTHCARE}

$\mathrm{BD}$ undoubtedly brings tremendous benefits for medical institutions if implemented correctly in the healthcare context, but its implementation involves many challenges from various sides.

3.1. Expertise barriers (EB): The absence of technical information can prompt the associations' inability to actualize technological developments. Practically all organizations endeavor to procure a severe level of specialized specialization and a low degree of specialized adaptability simultaneously. [10] Many expected and unforeseen difficulties have deterred clinics from creating BD clinical innovation because of a severe absence of technical information.

3.2. Operation Barriers (OB): This identifies with the issue of overspecialization and protection from authoritative change, especially those identified with creation and activity instead of innovative work [11]. This sort of obstruction is looked at by numerous associations, particularly when they have profoundly full capacities, bringing about a sensation of hesitance to change their exercises to actualize some advancement. In this manner, concerning information creation and the executives, the fame of $\mathrm{BD}$ is developing.

3.3. Resource barrier (RB): The essential factor for guaranteeing the early achievement of advancement execution might be many abundances. [12] Additionally, clinical BD frameworks' performance is expensive because of the absence of information normalization, the sheer volume of information, and the weakness of gadget networks. 
3.4. Regulation barriers (RUB): Guidelines can happen in different structures, and in any event, one such guideline applies to most enterprises. Rules for organizations have been arranged into four primary sorts: self-guideline of industry (codes of corporate leaders and morals), government guidelines, guidelines of asset imposing business models, and brand name guidelines.[13] Even though it is difficult to make clinical BD without the limitation of rules, the plan and utilization of clinical BD have not been plainly and effectively characterized.

\subsection{Market Access Barriers (MAB): Barriers to advertise} section commonly apply to all obstructions that limit innovations from arriving at open buyers. When the overall advancement industry is phenomenal, these obstructions become less applicable [14]. Before being dispatched, the FDA should examine each clinical item under exacting quality and security the board guidelines. The snag to showcase access exists because the FDA requires an impressive consumption in R\&D capital and preliminary clinical time.[15]

\section{RESEARCH METHODOLOGY}

The sample was chosen from every layer through the simple random sampling strategy as it permits populace congruity from the subpopulation [16] A 7.0 Likert scale had been used to examine different reactions that reach from 'strongly agree' to 'firmly concur'. The polls were shipped off 461 respondents. However, just 308 respondents returned usable surveys, substantial for investigation. To avoid a typical strategy, the examination group's inclination has played it safe during the pre-information assortment stage.[17] To check whether the collected data is basined or performed a single factor Harman test. The first factor of the EFA explains $32.588 \%$ of the variance, which is below the $50 \%$ level of recommendation [18] Table I shows the percentage of the demographics of respondents.

\section{TABLE 1: DEMOGRAPHICS OF THE RESPONDENTS}

\begin{tabular}{|l|l|}
\hline Characteristics & Percentage \\
\hline Gender of the respondents \\
\hline Male respondents & 63 \\
\hline
\end{tabular}

\begin{tabular}{|l|l|}
\hline Female respondents & 37 \\
\hline Current Position of the respondents \\
\hline Doctors in the hospitals & 42 \\
\hline IT manager in the hospitals & 37 \\
\hline Medical Officers in the hospitals & 21 \\
\hline
\end{tabular}

\section{DATA ANALYSIS}

\section{RELIABILITY AND VALIDITY}

\subsection{Cronbach's Alpha}

Cronbach's alpha (a) was used to perform the reliability test for each factor. Over the suggested worth of 0.70 , the upsides or dimensional scales should be. As shown in Table II, the values are more significant than 0.70 of the threshold levels. [19]

\subsection{Composite Reliability}

Composite reliability (CR) was additionally estimated for every one of the parts. It is assessed for inside consistency dependability given its capacity to give better outcomes. The builds' CR esteems > 0.7 demonstrates that the composite dependability measures are solid [20], as displayed in Table II.

\section{EXPLORATORY FACTOR ANALYSIS (EFA)}

$\mathrm{KMO}$ an incentive for the flow research is 0.857 . The importance esteem is 0.000 , which is under 0.05 , i.e., the likelihood esteem level worthy. The extraction technique utilized was principal axis factoring. [21] For the parts, the level of all-out difference was explained by segment 1 (36.115\%), segment 2 (10.342\%), segment 3 (8.768\%), segment $4(8.486 \%)$, and segments $5(6.110)$. The combined all-out difference clarified by each of the three elements is $69.730 \%$.

The Rotated Component Matrix is significant for deciphering the after effects of the examination. Turn helps gather the things, and each gathering contains multiple items in any event, which improves the design. Subsequently, this is the point of the objective of turn. In this examination, we have accomplished this point. Eighteen fundamental factors were assembled under five individual parts, as displayed in Table II. 
TABLE II: VALUES OF A, VALUES OF CR, VALUES OF ROTATED COMPONENT MATRIX

\begin{tabular}{|c|c|c|c|c|}
\hline Variable & Indicators & a & CR & Rotated Component Matrix \\
\hline \multirow{4}{*}{ OB } & OB1 & \multirow{4}{*}{0.847} & \multirow{4}{*}{0.889} & .784 \\
\hline & OB2 & & & .846 \\
\hline & OB3 & & & .873 \\
\hline & OB4 & & & .762 \\
\hline \multirow{4}{*}{$M A B$} & $M A B 1$ & \multirow{4}{*}{0.860} & \multirow{4}{*}{0.893} & .845 \\
\hline & MAB2 & & & .846 \\
\hline & MAB3 & & & .829 \\
\hline & MAB4 & & & .767 \\
\hline \multirow{4}{*}{ EB } & EB1 & \multirow{4}{*}{0.830} & \multirow{4}{*}{0.886} & .842 \\
\hline & EB2 & & & .773 \\
\hline & EB3 & & & .778 \\
\hline & EB4 & & & .853 \\
\hline \multirow{3}{*}{ RUB } & RUB1 & \multirow{3}{*}{0.840} & \multirow{3}{*}{0.902} & .844 \\
\hline & RUB2 & & & .953 \\
\hline & RUB3 & & & .803 \\
\hline \multirow{3}{*}{ RB } & RBI & \multirow{3}{*}{0.713} & \multirow{3}{*}{0.838} & .839 \\
\hline & RB2 & & & .881 \\
\hline & RB3 & & & .654 \\
\hline
\end{tabular}

\section{DISCUSSION}

BD in healthcare helps manage the massive volume of information created, like collecting patient records, etc. [13] But on the other hand, they face many challenges in the hospitals' adoption process. As this technology is new to everyone, they have lacked resource people. From the literature, we identified five challenges the BD faces in the adoption process. The first was an expertise barrier that refers to a lack of experience handling big data software. Employees do not have proper training, showing change resistance to adopting this technology. So, the top administration needs to decide on the training and motivate its adoption.

The second is the operation barriers facing privacy and IT infrastructure employees and top management face [12] Many hospitals do not have the proper IT infrastructure for adopting this technology. The third barrier, the resource barrier, refers to the project's cost arrangement problems. [15] The fourth barrier is regulation barriers, as the organizations need to follow the government guidelines to adopt the latest technology. Modifications and regulations of laws and policies in the healthcare sector create difficulties in applying medical BD technologies.[14] The fifth barrier, market access barriers, refers to problems the market faces and the competitor side. Healthcare BD has also raised numerous challenges in accepting and implementing medical institutions.

\section{CONCLUSION}

This research aims to find out the problems faced in the healthcare sector for the adoption process of BD. From the literature, five challenges were identified. For analysis, exploratory factor analysis is used, which helped group the variables into five groups. The finding of the study was also supported from another research. There are some limitations to the study, and also this can be extended further. We can extend this research and develop a structural equation model for the analysis. This research can be extended to some other sectors also. 


\section{References}

1. P. T. Chen, C. L. Lin, and W. N. Wu, "Big data management in healthcare: Adoption challenges and implications," Int. J. Inf. Manage., vol. 53, no. December 2019, p. 102078, 2020, doi: 10.1016/j.jijinfomgt.2020.102078.

2. S. Dash, S. K. Shakyawar, M. Sharma, and S. Kaushik, "Big data in healthcare: management, analysis and future prospects," J. Big Data, vol. 6, no. 1, 2019, doi: 10.1186/s40537-019-0217-0.

3. R. Johnson, "Predicting clinicians' intentions towards the electronic health record (EHR): an extended UTAUT model," no. March 2020, [Online]. Available: https://repository.up.ac.za/handle/2263/75255.

4. J. Aversa, T. Hernandez, and S. Doherty, "Incorporating big data within retail organizations: A case study approach," J. Retail. Consum. Serv., vol. 60, May 2021, doi: 10.1016/j.jretconser.2021.102447.

5. J. Ranjan and C. Foropon, "Big Data Analytics in Building the Competitive Intelligence of Organizations," Int. J. Inf. Manage., vol. 56, p. 102231, Feb. 2021, doi: 10.1016/j.ijinfomgt.2020.102231.

6. R. Y. Zhong, S. T. Newman, G. Q. Huang, and S. Lan, "Big Data for supply chain management in the service and manufacturing sectors: Challenges, opportunities, and future perspectives," Comput. Ind. Eng., vol. 101, pp. 572-591, Nov. 2016, doi: 10.1016/j.cie.2016.07.013.

7. S. SA, "Big Data in Healthcare Management: A Review of Literature," Am. J. Theor. Appl. Bus., vol. 4, no. 2, p. 57, 2018, doi: 10.11648/j.ajtab.20180402.14.

8. H. Al-Dmour, N. Saad, E. Basheer Amin, R. Al-Dmour, and A. Al-Dmour, "The influence of the practices of big data analytics applications on bank performance: filed study," VINE J. Inf. Knowl. Manag. Syst., vol. ahead-of-p, no. ahead-of-print, Feb. 2021, doi: 10.1108/vjikms-08-2020-0151.

9. M. Ghasemaghaei, "Understanding the impact of big data on firm performance: The necessity of conceptually differentiating among big data characteristics," Int. J. Inf. Manage., vol. 57, p. 102055, Apr. 2021, doi: 10.1016/j.ijinfomgt.2019.102055.

10. W. Li et al., "A Comprehensive Survey on Machine Learning-Based Big Data Analytics for IoT-Enabled Smart Healthcare System," Mob. Networks Appl., vol. 26, no. 1, pp. 234-252, Feb. 2021, doi: 10.1007/S1 1036020-01700-6/FIGURES/5.
11. A. Rehman, S. Naz, and I. Razzak, "Leveraging big data analytics in healthcare enhancement: trends, challenges and opportunities," Multimed. Syst. 2021, vol. 1, pp. 1-33, Jan. 2021, doi: 10.1007/S00530-02000736-8.

12. M. Au-Yong-Oliveira, A. Pesqueira, M. J. Sousa, F. Dal Mas, and M. Soliman, "The Potential of Big Data Research in HealthCare for Medical Doctors' Learning," J. Med. Syst., vol. 45, no. 1, pp. 1-14, Jan. 2021, doi: 10.1007/S10916-020-01691-7/TABLES/2.

13. R. Spanò and G. Ginesti, "Fostering performance management in healthcare: insights into the role of big data," Meditari Account. Res., 2021, doi: 10.1108/MEDAR-12-2020-1123/FULL/PDF.

14. M. Rashid, H. Singh, V. Goyal, S. A. Parah, and A. R. Wani, "Big data-based hybrid machine learning model for improving performance of medical Internet of Things data in healthcare systems," Healthc. Paradig. Internet Things Ecosyst., pp. 47-62, Jan. 2021, doi: 10.1016/B978-0-12-819664-9.00003-X.

15. L. T. Majnarić, F. Babič, S. O'sullivan, and A. Holzinger, "Al and Big Data in Healthcare: Towards a More Comprehensive Research Framework for Multimorbidity," J. Clin. Med. 2021, Vol. 10, Page 766, vol. 10, no. 4, p. 766, Feb. 2021, doi: 10.3390/JCM10040766.

16. M. M. Baral, R. K. Singh, and Y. Kazançoğlu, "Analysis of factors impacting survivability of sustainable supply chain during COVID-19 pandemic: an empirical study in the context of SMEs," Int. J. Logist. Manag., 2021, doi: 10.1108/IJLM-04-2021-0198/FULL/PDF.

17. M. M. Baral and A. Verma, "Cloud Computing Adoption for Healthcare: An Empirical Study Using SEM Approach," FIIB Bus. Rev., vol. 10, no. 3, pp. 255-275, Sep. 2021, doi: 10.1177/23197145211012505.

18. S. Mukherjee, M. M. Baral, V. Chittipaka, S. C. Srivastava, and S. K. Pal, "Discussing the Impact of Industry 4.0 in Agriculture Supply Chain," Lect. Notes Mech. Eng., pp. 301-307, 2021, doi: 10.1007/978-98116-3033-0_28.

19. S. Mukherjee and V. Chittipaka, "Analysing the Adoption of Intelligent Agent Technology in Food Supply Chain Management: An Empirical Evidence," FIIB Bus. Rev., p. 2319714521 10592, Nov. 2021, doi: $10.1177 / 23197145211059243$. 
20. S. Mukherjee, V. Chittipaka, and M. M. Baral, "Developing a Model to Highlight the Relation of Digital Trust with Privacy and Security for the Blockchain Technology," in Blockchain Technology and Applications for Digital Marketing, IGI Global, 2021, pp. 110-125.

21. S. K. Pal, M. M. Baral, S. Mukherjee, C. Venkataiah, and B. Jana, "Analyzing the impact of supply chain innovation as a mediator for healthcare firms' performance," Mater. Today Proc., Nov. 2021, doi: 10.1016/j.matpr.2021.10.173.

22. A. Kumar, P. Pujari, N. Gupta (2021): Artificial Intelligence: Technology 4.0 as a solution for healthcare workers during COVID-19 pandemic, Acta Universitatis Bohemiae Meridionalis 24 (1), 23-42

23. N. Ayedee, A. Kumar, A. Buttan, and A.A. Shaikh (2021): Asmat Ara, Role of Emotional Intelligence and Strategic Human Resource Management during COVID-19 Pandemic, Academy of Strategic Management Journal 2021, https://ssrn.com/abstract=3884429.

24. A. Kumar, N. Ayedee (2021): An Interconnection between COVID-19 and Climate Change Problem, Journal of Statistics and Management Systems 24 (2), $1-21$.

25. S.K. Pal, A.K. Pal (2021): The impact of increase in COVID-19 cases with exceptional situation to SDG: Good health and Well-being, Journal of Statistics \& Management Systems 24 (1), 209-228.

26. A. Kumar, N. Ayedee (2020): Technology Adoption: A Solution for SMEs to overcome problems during COVID-19, Academy of Marketing Studies Journal 25 (1), 1-16. 